Altai State University

Acta 3iologica Gibirica

Journal of Biology

Founded in 2015

\title{
Assessment of the impact of seasonal patterns climatic conditions on spawning events of the white bream Blicca bjoerkna (Linnaeus, 1758) in astronomical and biological time
}

\author{
D. Bondarev' ${ }^{1}$ O. Kunah², O. Zhukov ${ }^{2}$ \\ 1 "Dnipro-Orylskiy" Nature Reserve 52030 Obukhovka, Dniprovsk district, Dnipropetrovsk region, Ukraine; \\ e-mail: ihtio72log@ukr.net \\ ${ }^{2}$ Department of Zoology and Ecology, Oles Honchar Dnipro National University, pr. Gagarina, 72, 49010 Dnipro, \\ Ukraine; e-mail: zhukov_dnipro@ukr.net, olga-kunakh@rambler.ru
}

\begin{abstract}
This paper describes spawning events of the white bream Blicca bjoerkna (Linnaeus, 1758 )in astronomical and biological time depending on seasonal patterns of climatic conditions. The research was conducted in the "Dnipro-Orilskiy" Nature Reserve (Ukraine) during the years 1997-2015 in four habitat types. The timing of the spawning event (start, end) was evaluated using astronomical time (number of days from January 1 each year), with correction for the lunar and the semilunar cycle, and using biological time (number of days from the end of spawning in the previous year to the beginning and end of spawning in the current year). The spawning phenology of the white bream was found to be dependent on the dynamics of weather conditions over time. Patterns of varying climatic regimes which are expressed by means of multivariate principal component are the most informative predictors of the spawning events. Evaluation of occurrence of spawning events in astronomic or biological time gives somewhat different models of the impact of climate regimes. The impact of the principal components indicating variability of rainfall during the year in which spawning occurs is statistically significant for almost all regression models. Models using the solar calendar are also more sensitive to the course of air temperatures within the year when spawning occurred. Correction of time based on the lunar cycle allows us to assess events which are sensitive also to the temperature and rainfall variation during the second half of the previous year. Biological time was shown to be sensitive to environmental influences over time from the end of spawning in the previous year to spawning in any given year.
\end{abstract}

Key words: spawning, white bream, dynamics, climate, global warming, astronomical time, biological time

\section{Introduction}

The modern doctrine of the biosphere is a largely empirical generalization of V.I. Vernadsky (1923, 1926), according to which the concept of biosphere includes not only the sphere of life, but also other structures of the Earth, which are genetically related to living matter (Sokolov, 2010). If the biosphere is the global biotope, the global biocoenosis is geomerida (Beklemishev, 1928). Geomerida is also seen as the single organism of the Earth (Lyubishchev, 1982). Some general ideas in the field of philosophy and biology in the early twentieth century are particularly important now at a time when global climate change includes synchronous changes in living systems at different hierarchical levels.

In the seasonal world, organisms adapt to the recurring periodic changes caused by geophysical cycles (Bradshaw \& Holzapfel, 2007, 2010; Foster \& Kreitzman, 2009). Understanding of the dynamics of phenological processes and seasonal timing in the context of global climate change is of particular relevance (Visser et al., 2010, Forrest \& Miller-Rushing, 2010). 
Environmental variables which throughout the evolution process have created selective pressures that restrict certain activities within a defined time period can be classified as ultimate causes (Baker, 1938; Thompson, 1950). These factors may be fundamentally different depending on the species and seasonal activity of the organism. Even a single type of seasonal activity can be controlled by several ultimate causes (Gwinner, 1981). Organisms have different mechanisms that are based on annual cycles, but in general combine internal time-keeping with signals from external cues in preparation for the forecast annual changes in their environment (Helm et al., 2013).

Reproduction is an important ecological process that ensures population abundance and conservation of the species. Adaptation of fish to breeding conditions and their development reflect not only the basic environmental conditions of water, but also features of the other significant life cycle phases of the species (Kryizhanovskiy, 1949). Phenological indicators of the reproduction of fish characterize the biological status of the population and may reveal the presence of a microevolution process and fully reflect processes of population homeostasis, their nature and direction (Nikolskiy, 1974). According to the general model, the salmon reproductive cycle is mainly regulated by duration of the photoperiod and the carp fish reproductive cycle is regulated by temperature (Billard et al., 1978). The temperature of the water environment is a critical factor that influences the development of fish (Brett, 1979; Herzig \& Winkler 1986; Jobling, 2003). Temperature also affects the characteristics associated with reproduction of fish, namely the definition of the sex, gametogenesis dynamics, gametes quality, fertility, age, sexual maturity and the duration of the reproductive season (Breton et al., 1980; Billard, 1986; Jafri, 1989; Sandström et al., 1995; Alavi \& Cosson, 2005; Lahnsteiner \& Mansour 2012; Domagała et al., 2013). Changes in the timing of fish spawning can be indicators of climate change (Schneider et al., 2010). Rising temperatures due to global climate change stimulate an earlier timing of spawning bream, but the spawning of roach occurs in the same period as in that of climate change (Noges \& Jarvet, 2005). In the spring, which is characterized by the most significant changes related to global warming, the vast majority of fish species undergo their spawning (Noges \& Jarvet, 2005). Changes in spawning phenology could lead to the desynchronization with the plankton development and the cascading effects on food chains, which may have consequences for the entire ecosystem (Blenckner, 2001; Edwards \& Richardson, 2004). Deficiency in reliable long-term data on fish spawning explains why there is a much smaller number of publications on the phenology of fish compared to the phenology of birds, butterflies and terrestrial plants (McCarty, 2001; Noges \& Jarvet, 2005).

Precipitation may also act as a significant factor. More frequent and more intense rainfall, which may be the result of anthropogenic climate change, have numerous effects such as the transportation of pollutants into the hydrological cycle, the addition of excess nutrients into water bodies, increase in sediment load and eutrophication (Crozier \& Hutchings, 2014). These inputs can reduce the water quality for fish and cause harmful algal blooms and the creation of hypoxic «dead zones» (NCADAC, 2013).

Most types of seasonal activity cannot begin as soon as the ultimate causes reach critical levels since a relatively long period is required for these causes to take effect, which is particularly evident in the case of reproduction. In many organisms there are developed strategies for reliable warning signals that vary in strict accordance with the "ultimate" factors for controlling seasonal activity (Gwinner, 1981). These cues actually control the annual cycles of influence on physiological processes called "proximate causes" (Baker, 1938). Although ultimate factors affect the forecasted annual cyclical biological processes, natural selection promotes the development of mechanisms that allow organisms to anticipate changes in environmental conditions on the basis of their internal biological clock and the external opportunities to perceive warning signals (Immelmann, 1971).

The rhythm resulting from impacts on the Earth in different phases of the lunar cycle may act as a proximate cause. The moon's position relative to the Earth and Sun gives rise to certain cycles that occur at regular intervals. The synodal lunar cycle (from full moon to full moon) has a duration of 29.5 days and has a number of effects on changes in the environment that can be perceived by animals. For example, changes in the intensity of moonlight, gravity changes and changes in geomagnetic fields (Phillips, 1986; Lohmann \& Willows, 1987; Fischer et al., 2001; Grant et al., 2009). Typically, certain events in the life cycle of fish are associated with the phases of the lunar cycle (McDowall, 1969).

Phenological changes in the lives of organisms are the result of the interaction of regular processes of biotic and abiotic nature (Bondarev \& Zhukov, 2017). Typically, phenological research compares the effects of the environment in a given time on the corresponding events in the dynamics of biological systems. Synchronous processes, such as correspondence between rhythmic and quasi-regular changes in the environment and biological processes which exist for a long time have remained outside the attention of researchers. However, it should be noted that anthropogenic environmental changes result not only in changes in the total characteristics of the environment (increase in average temperature and increase or decrease in rainfall), but also to transformation in patterns of seasonal rhythm of the course of temperatures and precipitation. Hydroclimatic variables such as seasonal course of rainfall and temperature are features of the climate within river basins (Mbungu et al., 2012; Ouarda et al., 2014). In this context, study of the phenology of fish, such as spawning, against the background of holistic patterns of climatic conditions, is of particular interest.

A specific feature of biological systems is the high level of organization of their own time (Mikhailovsky, 1995). The metaphor of physical time is "time's-arrow", the biological metaphor of time is the "time's cycle" (Günther \& Morgado, 2004). A particular problem is the procedure for the timing of phenological events. Time depends on the zero point and units of time. As the time units for describing annual phenological processes we use the term day. The day is a unit of astronomical time, but there are other alternative units of biological time. Terms of spawning can be measured as a 
number of days from the start of the new astronomical year to spawning events (Noges \& Jarvet, 2005). Time of the "new year" can be adjusted on the basis of the lunar or semilunar cycle. You can also keep a record of biological time as the time between biological events (from end of spawning in the previous year to the beginning of spawning in the following / current year and also spawning duration).

The object of our study is to investigate dependence of spawning events of the white bream Blicca bjoerkna (Linnaeus, 1758) in astronomical and biological time on seasonal patterns of climatic conditions.

\section{Materials and Methods}

Physiographic features of the "Dnipro-Orylskiy»Nature Reserve

In order to preserve the unique landscape of the Valley of the Middle Dnipro and the River Oril with its characteristic complex of flora and fauna "the Dnipro-Orylskiy" Nature Reserve was created in 1990. Today it is the only strict nature reserve (zapovednik) in the Dnipropetrovsk region of Ukraine. The reserve protects the landscapes and the biodiversity of the valley of the Dnipro and its tributary the River Oril. The total area of the reserve is 3,766.2 hectares, and about $30 \%$ of this is covered by water, most of which is unique floodplain lakes (Bondarev \& Zhukov, 2017).

The reserve is located on the upper area of the Dnipro reservoir, which has suffered considerable anthropogenic transformation (Sharamok et al., 2017). This has created the need for comprehensive ichthyological research to determine the direction and depth of the processes that occur in populations of fish influenced by the actions of the aggregate anthropogenic factors (Bondarev, 2007). Research on the fish fauna of the reserve enables us not only to identify the composition of the fish fauna and the character of its distribution in the water bodies but also to reveal the direction of the processes that are taking place in the ecosystem in general (Bondarev, 2007).

\section{Biotopes}

Information about fish spawning was collected in the following locations (Fig. 1).

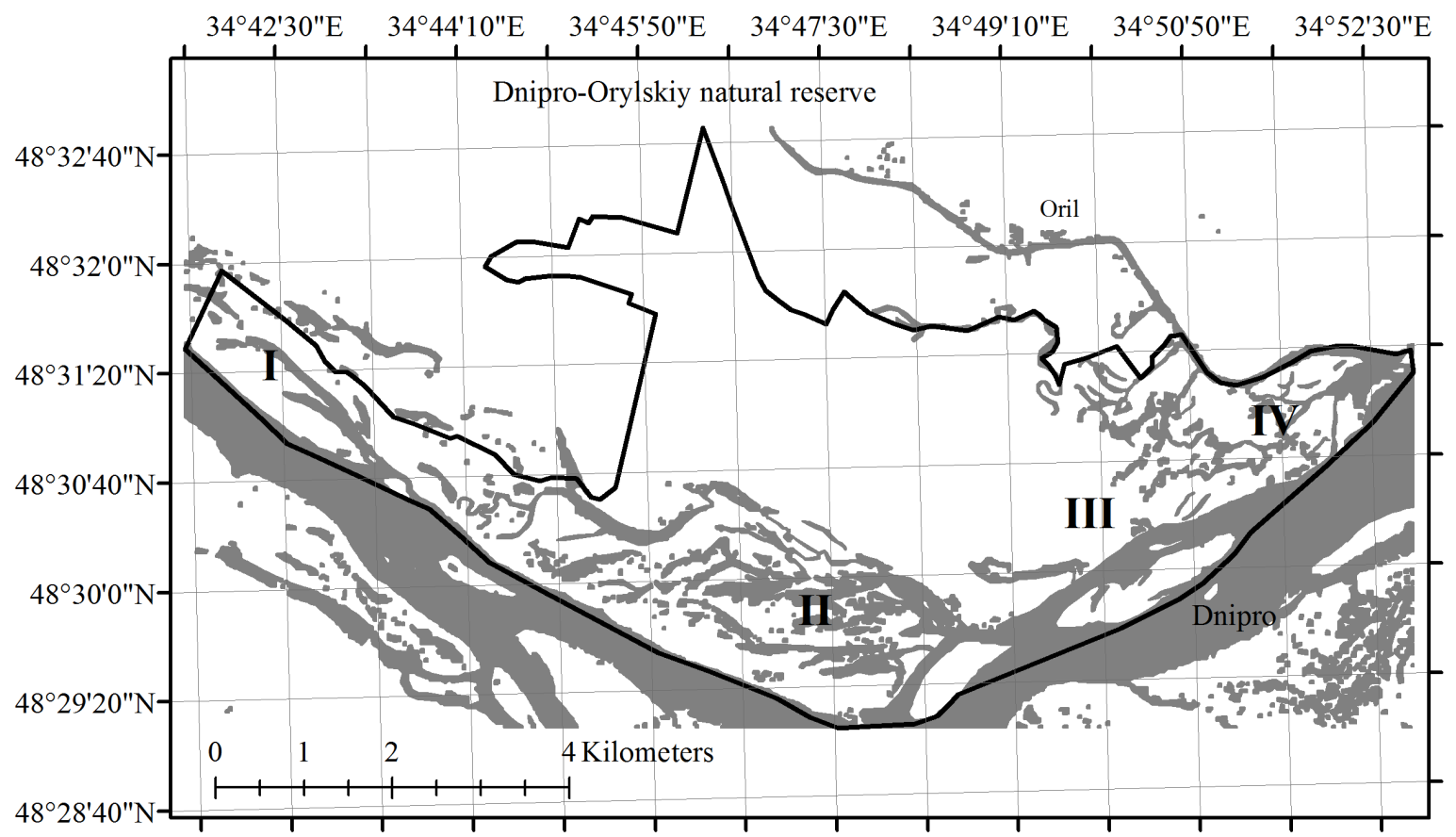

Fig. 1. Map of the "Dnipro-Orylskiy»Nature Reserve and spawning locations

I - Nikolayev system of water bodies; II - Water bodies of the Taromske ledge; III - The channel of the Dnipro; IV River Protoch system and Obukhov floodplain.

Nikolayev system of water bodies. The system of flood waters, located in the narrowest part of the floodplain terraces. The water bodies extend in a narrow strip extending along the flow the Dnipro. The maximum distance from the Dnipro within the reserve is about 300-1000 meters. Characterized by high level of flow and drop in the water level during the day, depending on the operating conditions of the reservoir. Part of the water body, connected with individual channels specified area, is located outside the reserve. Shallow areas (littoral zone) are minimal. Maximum depth is 5.6 meters. In recent years, the water in the central part of this area have been actively silted up with sandy sediment due to the accumulation of excess sandy deposition in areas outside the reserve and the formation of new sand spits and islands.

River Protoch system and Obukhov floodplain. Most of the ponds are poorly flowing, shallow waters which are remnants of the lower parts of the Protovch creek which united the Dnipro with the old course of the Orel. The ponds were flooded due to the formation of the reservoir. The water regime of the Protoch system and the Obukhov floodplain is under significant influence of the water regime of the reservoir. The water bodies are characterized by significant silting 
Bondarev, D. et al. Assessment of the impact of seasonal patterns climatic... Acta Biologica Sibirica, 2018, 4(2), 61-77

(in some places the thickness of silt accumulation reaches 0.6-1.0 m) and growth of higher aquatic vegetation. The system is connected with the Dnipro and the estuary of the Orel by narrow streams. The greatest distance between the Dnipro and the Orel within this section is about $2 \mathrm{~km}$.

The channel of the Dnipro. Includes the area of the upper Dnipro reservoir, which partially retains a river regime. The area studied is along the left bank between Krachynyy and Kamyanisty islands. Biotopes are characterized by high level of changing in water levels and moving sand masses associated with active formation of channel process at the site of the reservoir. Depths range between 2-7 meters. Between these islands is part of the rock ridge that stretches from the right bank of the Dnipro left bank.

Water bodies of the Taromske ledge. The system of flood waters, located in the lowest part of the floodplain terraces is a unique floodplain biogeocoenosis in the steppe Dnipro region. According Pervukhin's (1979) genetic classification it is an example of the oxbow lakes formed in the Dnipro floodplain. All lakes are separated from the Dnipro bed by a belt of sand and connected by multiple channels, directly related to the channel of the Dnipro. Most ponds have a significant littoral zone that is actively covered with higher aquatic vegetation. Depths range between 1-10 meters. Water exchange is carried out through the operation of the reservoir and spring floods. Maximum distance of these ponds from the Dnipro river is about two kilometers. At present, the ponds of the specified area are actively swamping and silting due to unbalanced operation of the reservoir. In some parts the thickness of silt reaches $0.3-0.7 \mathrm{~m}$.

The biological characteristics of white bream Blicca bjoerkna (Linnaeus, 1758)

As the model object we selected the white bream. This species is widely distributed and moderately abundant in waters of the reserve (Bondarev \& Zhukov, 2017). White bream can be attributed to the category of common species.

White bream Blicca bjoerkna (Linnaeus, 1758) is a common species of cyprinidae fish in freshwater pools in almost the whole of Europe and Asia (Berg, 1949; Tadajewska, 2000; Kottelat \& Freyhof 2007). Its wide distribution is evidence of the important functional role of this species in supporting sustainability of aquatic ecosystems (Kompowski \& Neja, 1999). White bream is a limnophilic species and is found in large lakes or in the lower reaches of rivers (Kottelat \& Freyhof, 2007). This species is euryphagous and feeds mainly on invertebrate benthos. Zooplankton, mollusks and Chironomidae form the diet of white bream (Wielgosz \& Tadajewska, 1988). Consumption of zooplankton by white bream contributes to reducing the level of eutrophication of those water bodies where this species lives (Beklioglu et al., 2011). White bream is one of the targeted species selected for biomanipulation in eutrophicated lakes (Prejs et al., 1994).

The white bream spawning season is extended in time, and the egg laying occurs several times, usually in two or three series (Tadajewska, 2000). Some females have an undefined fertility and have one or several episodes of single spawning during the reproductive season (Kopiejewska \& Kozłowski, 2007). Spawning can last 35-75 days (Kopiejewska, 1996), or 21-52 days (Spivak, 1987). The number of eggs deposited depends on the number of fish in the volume of water in the reservoir at any given latitude (Mann et al., 1984). Spawning usually takes place in May-June at temperatures above $15^{\circ} \mathrm{C}$ (Kottelat \& Freyhof, 2007). Spawning of the white bream in different regions of Europe takes place in a similar period from the beginning of May to the end of June, or even to the beginning of July in Poland (Domagała et al., 2015), Northern Russia (Berg, 1949), Belgium (Rinchard \& Kestemont ,1996; 2003), Germany (Spratte \& Hartmann, 1997; Molls, 1999). The earliest spawning was recorded in Turkey in April (Y.lmaz et al., 2012; 2015; Okgerman et al., 2012). Spawning only in May has been observed in the waters of Russia (Slastenenko, 1956) and Austria (Hacker, 1979). The longest term of spawning in July was observed for Finland (Koli et al., 1990) and Turkey (Okgerman et al., 2012).

Methods spawning phenology

The materials that formed the basis of this research were gathered from the waters of the reserve in the years 19972015. Sampling was conducted using a standard set of fishing gear (nets with mesh size 30 to $90 \mathrm{~mm}$ ) in different parts of the waters of the reserve. All work associated with the removal of fish from natural water bodies was conducted in accordance with current norms and regulations by standard ichthyological methods (Arsan et al., 2006; Chugunova, 1952; Pravdin, 1966).

During the research we conducted full or part-biological analysis of fish. We determined the species, size, weight, gender, stage of maturity of sexual products, and selected samples to determine the age and fertility. Determining the stage of maturity of sexual products actually allowed us to track phenological dates of the beginning of spawning of some fish species. All data was recorded in a special journal. Additionally, tracking of weather conditions, fluctuations in water level and water temperature was determined.

In addition, to obtain data on the characteristics and intensity of fish spawning we made visual observation and conducted planned survey routes through spawning grounds with stops every 20,50,100 m to check the vegetation and presence of fish eggs. If roe was found, the place of its location was described in detail. We noted the name of the water body, depth, water temperature, time of day, type of vegetation and richness of the spawning (Koblitskaya, 1963).

Data Phase Moon

The dates of full moons were obtained from the US Naval Astronomical Observatory Applications Department (http://aa.usno.navy.mil/data/docs/MoonFraction.php) for midnight Universal Time (GMT). Moon phase is independent of the geographical position of the observer (Grant et al., 2009).

Assessment of spawning events

The period of spawning (beginning and end) was estimated by the usual calendar. Calendar dates for statistical analysis were transformed in different ways. According to astronomical solar calendar, dates were converted into variables that represent the number of days from January 1 of each year to the spawning event (beginning and end). Date 
Bondarev, D. et al. Assessment of the impact of seasonal patterns climatic... Acta Biologica Sibirica, 2018, 4(2), 61-77

of the new year, and accordingly, the starting point can be adjusted by the lunar calendar. According to the lunar calendar, every year began with the count from the first new moon after January 1 of the given year. Variations of the lunar adjustment are semilunar correction: the zero point started with the first new moon or full moon after January 1 of the given year.

The alternative to astronomical time was biological timing, the beginning of which started since the end of the previous year's spawning. It should be noted that the duration of spawning in nature is an event which is calculated in biological time.

Meteorological data

We used the data from the meteorological observatory of the city Dnipro.

\section{Results}

White bream spawning began between April 29 and May 23 (at 118-142 days of the year), and ended between 20 May and 12 June (at 139-162 days) (Bondarev \& Zhukov, 2017). Thus, spawning lasts 10-30 days (Table 1).

Table 1. Descriptive statistics Blicca bjoerkna timing of spawning during 1997-2015 (N=72)

\begin{tabular}{|c|c|c|c|c|c|c|c|c|c|}
\hline \multirow{2}{*}{$\begin{array}{l}\text { Spawning } \\
\text { parameters }\end{array}$} & \multirow{2}{*}{ Mean \pm st. error } & \multirow{2}{*}{$\begin{array}{l}\text { Mini } \\
\text { mum }\end{array}$} & \multirow{2}{*}{$\begin{array}{l}\text { Maxi } \\
\text { mum }\end{array}$} & \multicolumn{2}{|c|}{ Confidence interval } & \multirow{2}{*}{$\begin{array}{l}\text { Skewness } \\
\pm \text { st. error }\end{array}$} & \multirow{2}{*}{$\begin{array}{l}\text { Kurtosis } \\
\pm \text { st. error }\end{array}$} & \multirow[t]{2}{*}{$\mathrm{K}-\mathrm{S} d$} & \multirow[t]{2}{*}{$p$-level } \\
\hline & & & & $-95 \%$ & $+95 \%$ & & & & \\
\hline Duration & $20.29 \pm 0.56$ & 10 & 30 & 19.17 & 21.41 & $0.21 \pm 0.28$ & $-0.57 \pm 0.56$ & 0.09 & 0.51 \\
\hline \multicolumn{10}{|c|}{ The number of days from the end of the spawning season previous year } \\
\hline Start & $345.42 \pm 0.70$ & 335 & 358 & 336.00 & 357.00 & $0.12 \pm 0.28$ & $-0.92 \pm 0.56$ & 0.10 & 0.36 \\
\hline \multicolumn{10}{|c|}{ The number of days from January 1 of each year } \\
\hline Start & $130.56 \pm 0.55$ & 118 & 142 & 129.45 & 131.66 & $-0.03 \pm 0.28$ & $0.46 \pm 0.56$ & 0.11 & 0.30 \\
\hline End & $150.85 \pm 0.67$ & 139 & 162 & 149.51 & 152.18 & $-0.05 \pm 0.28$ & $-0.86 \pm 0.56$ & 0.10 & 0.42 \\
\hline \multicolumn{10}{|c|}{ The number of days after January 1 , corrected on the basis of the lunar cycle } \\
\hline Start & $114.56 \pm 1.17$ & 91 & 132 & 97.00 & 132.00 & $0.09 \pm 0.28$ & $-0.78 \pm 0.56$ & 0.11 & 0.35 \\
\hline End & $134.85 \pm 1.17$ & 110 & 156 & 118.00 & 155.00 & $0.29 \pm 0.28$ & $-0.56 \pm 0.56$ & 0.09 & 0.56 \\
\hline \multicolumn{10}{|c|}{ The number of days after January 1, corrected on the basis of the semilunar cycle } \\
\hline Start & $123.44 \pm 0.69$ & 106 & 132 & 110.00 & 132.00 & $-0.83 \pm 0.28$ & $0.26 \pm 0.56$ & 0.15 & 0.10 \\
\hline End & $143.18 \pm 0.75$ & 127 & 156 & 130.00 & 156.00 & $-0.14 \pm 0.28$ & $-0.04 \pm 0.56$ & 0.07 & 0.81 \\
\hline
\end{tabular}

The distribution characteristics of the spawning are primarily symmetrical, since the coefficients of skewness do not differ statistically from zero (Fig. 2). An exception is the distribution of the values of the beginning of the spawning after the correction with regard to the semilunar cycle. In this case, the distribution has a tendency to shift to the left.

Kurtosis statistically was not different from zero for the distribution of spawning duration, the timing of the start of spawning by the solar calendar and after semilunar cycle correction, as well as the timing of the end of the spawning season according to the lunar and semilunar cycle correction. The specified distributions may be explained by the normal law as the best model according to the Smirnov-Kolmogorov criterion.
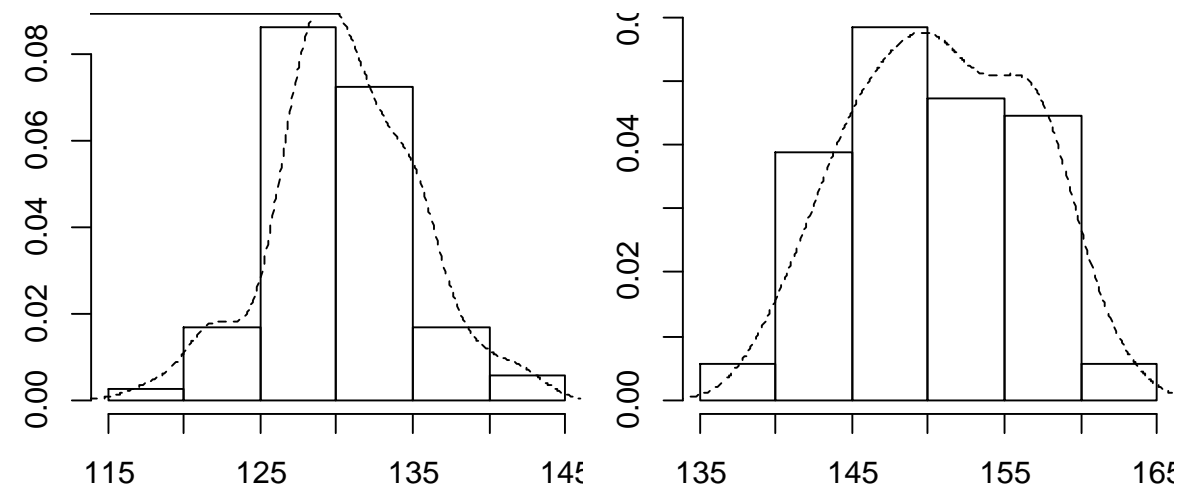

A

Start

End 

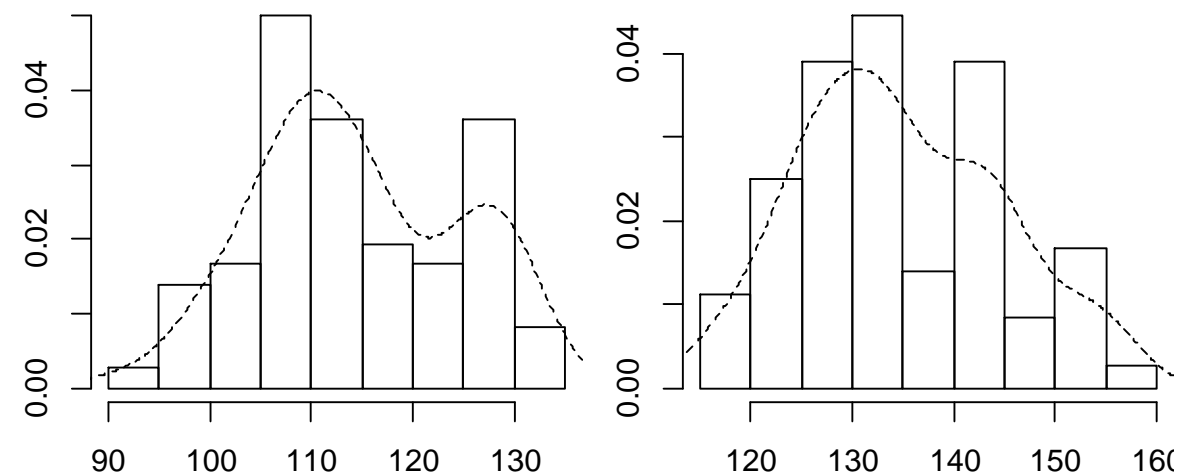

B
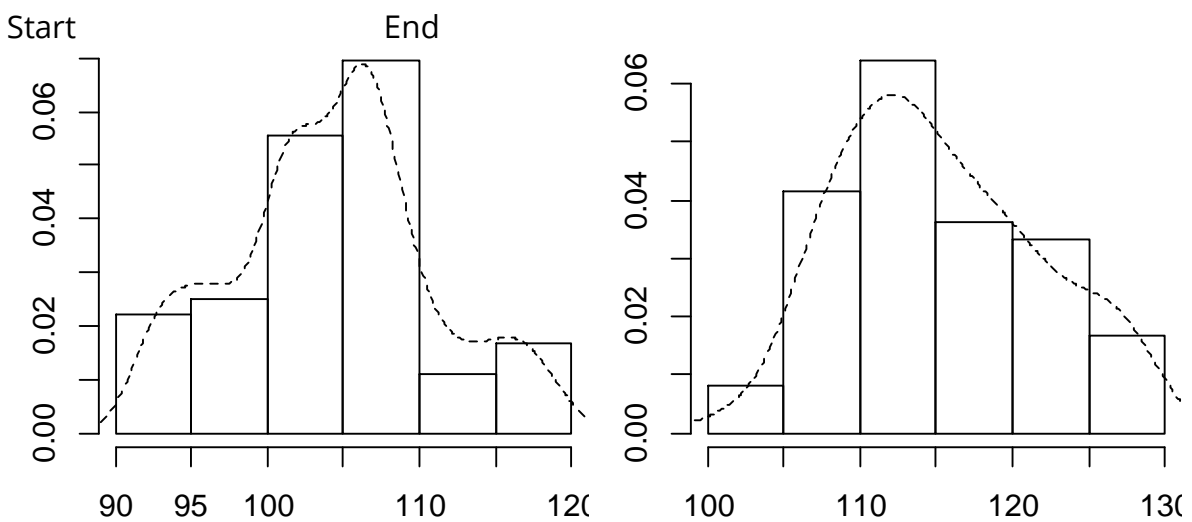

$\mathrm{C}$

Start End
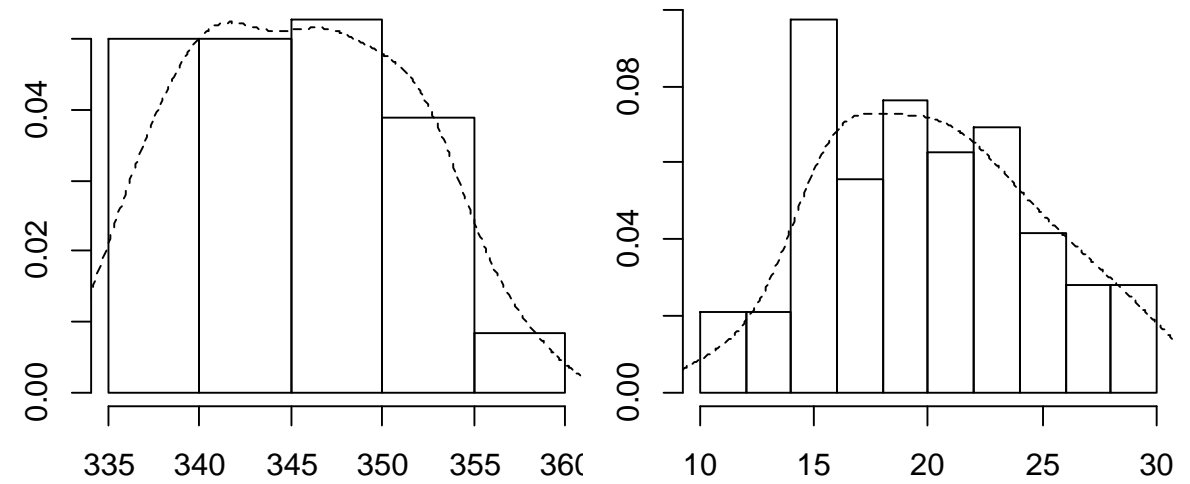

\section{D}

Fig. 2. Histogram Blicca bjoerkna spawning timing characteristics in the period 1997-2015.

A - solar calendar; B - solar calendar with lunar correction; C - solar calendar with semilunar correction; D spawning duration (number of days from the end of the last spawning)

Negative kurtosis of the spawning end distribution demonstrates a tendency to bimodality. The model is a mixture of two Gaussian distributions, which pretty well describes the following observation. For the distribution of the number of days from the end of the spawning season the previous year before the start of the spawning season in the current year the Kolmogorov-Smirnov statistic is $d=0.05, r=0.99$ with the parameters of the distribution: mean is $339.48 \pm 0.29$ (mixture coefficient is 0.37 ) and $348.83 \pm 0.49$ (mixture coefficient is 0.63 ). The distribution of the number of days until the end of the spawning season for the solar calendar is also a mixture of two distributions $(d=0.08, p=0.75$, means are $148.19 \pm 0.49$, mixture coefficient is 0.71 and $157.20 \pm 0.27$ mixture coefficient 0.25 ).

The correction of spawning time with consideration of the lunar cycle gives the estimations with distributions that are a mixture of two normal distributions. With the specified correction for the first distribution, the Kolmogorov-Smirnov statistic is $d=0.06, p=0.91$, mean is $110.25 \pm 0.80$, mixture coefficient is 0.76 and for second distribution mean is 128.21 \pm 0.27 , mixture coefficient is 0.24 . To end of spawning for the first distribution $d=0.94, p=0.06$, mean is $128.93 \pm 0.69$, mixture coefficient is 0.62 and for second distribution mean is $144.62 \pm 0.74$, mixture coefficient is 0.38 .

Analysis of meteorological data for the period of research has allowed us to identify the trends of variation of air temperature, which correlates with the temperature in water bodies. This relationship can be linear (Stefan \& Preud'homme, 1993), or when taking into account the evaporative cooling it is more complicated and non-linear (Mohseni \& Stefan 1999). The typical course of temperature throughout the year is characterized by the presence of two branches: the ascending and descending (Fig. 3). 


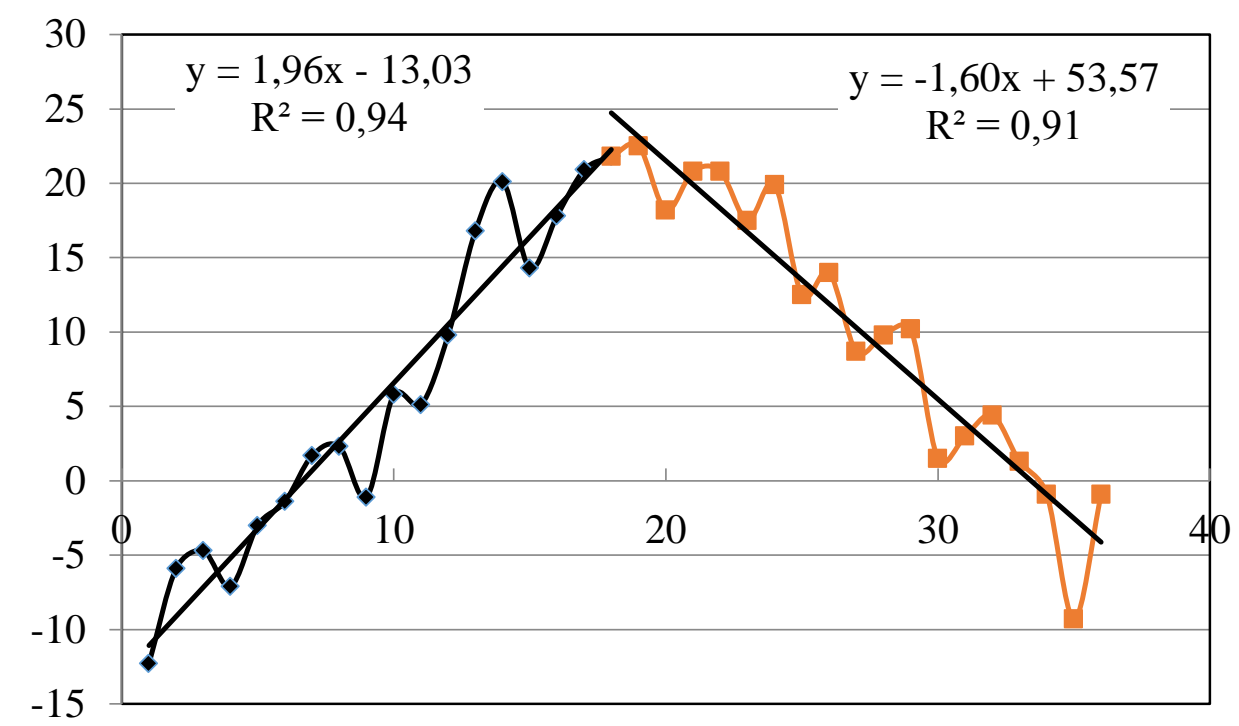

Fig. 3. Typical course of temperature throughout the year (as an example we give the data for 1997). Horizontal axis is the order of decades from the beginning of the year, vertical axis is the average temperature for the decade, ${ }^{\circ} \mathrm{C}$. Experimental points are connected using spline approximation. Straight lines indicate the trend of ascending branches of the temperature course (left) and descending branches of the temperature course (right) are estimated using linear approximation (see text).

The temperature course of a given year until the event (start of spawning, the end of spawning, spawning duration) and possibly temperatures course of previous year may be considered as being able to explain the timing of spawning events. Spawning events of a given year take place entirely within the ascending branch of the temperature course, which can be accurately described by a linear equation of the form:

$$
Y=a+b * X
$$

where $\mathrm{Y}$ is ten-day mean temperature; $\mathrm{X}$ is the order of decades for $\mathrm{I}-\mathrm{VI}$ months of the year, $a$ and $b$ are the parameters of the equation.

The same equation can be used for descending branches of the temperatures course for decades during the VII-XII months of the previous year.

Regression parameters and coefficients of determination have the following ecological sense. For the ascending branch, the smaller the regression coefficient $b$, the greater the contrast of temperatures in winter and summer. Due to the fact that linear approximation is a certain generalization of the sinusoidal natural course of temperature, it should be borne in mind that the highest summer temperatures are close to the point where the course of temperature moves from increase to decrease. Therefore, the coefficient $b$ largely will depend on the minimum winter temperatures and should be interpreted as a marker of the coldness of the winter. This interpretation is all the more justified because it is the assessment of the impact on fish spawning periods and processes that precede spawning events which has importance for their explanation. Changing the direction of the temperature course occurs after spawning, which is why it is not relevant for the explanation. If we consider a coefficient beyond the ecological context, then certainly this parameter depends both on the coldness of winter, and on summer heat. Similar considerations lead us to interpret the coefficient $a$ of a descending branch as a marker of summer heat. Comparison of the $a$ coefficients of linear regression for the ascending branch of the current year and the previous descending branch give the correlation coefficient between these parameters as $r=-0.10, p=0.39$. This result confirms our assumption that the $a$ coefficient of a descending branch is a marker of the summer heat, as if it were a marker of the winter coldness, the correlation coefficient of the regression parameters for branches of the temperatures course that are common for a given winter would be statistically significant. In addition, no correlation indicates that these factors provide independent and additional information about the weather conditions.

Coefficient $a$ of the regression model for the ascending branch characterizes the rate of warming during the spring, i.e. the summer speed. For the descending branch, this coefficient indicates the rate of cooling in the fall, which speeds the onset of winter. The linear model reflects the general trend of warming in spring and autumn cooling. In reality, temperature variation is a complex oscillatory process. Because coefficient of determination of linear regression is a measure of the global fit of real process to linear model. Significant deviations from the general trend lead to a reduction in the coefficient of determination. These variations are the result of processes of sharp warming, alternating with periods of abrupt cooling. The more frequent such events, the smaller the coefficient of determination.

Thus, to describe the timing of spawning occurrence events we can examine the impact on them of such factors as regression model parameters for the current year for the ascending branch of the temperatures course and parameters for the model for the previous year for descending branches of the temperatures course (Table 2). 
Table 2. The parameters of the regression models of the temperature courses during the year

\section{The parameters of the regression models}

Year For ascending branch

$\begin{array}{llll} & a_{1} & b_{1} & R^{2} \\ 1997 & 1.96 & -13.03 & 0.94 \\ 1998 & 1.74 & -8.91 & 0.88 \\ 1999 & 1.62 & -6.93 & 0.90 \\ 2000 & 1.71 & -9.24 & 0.89 \\ 2001 & 1.36 & -5.51 & 0.81 \\ 2002 & 1.62 & -6.87 & 0.94 \\ 2003 & 1.95 & -12.99 & 0.85 \\ 2004 & 1.45 & -6.84 & 0.89 \\ 2005 & 1.61 & -8.32 & 0.76 \\ 2006 & 2.06 & -14.29 & 0.91 \\ 2007 & 1.61 & -6.41 & 0.79 \\ 2008 & 1.75 & -9.23 & 0.95 \\ 2009 & 1.81 & -9.76 & 0.93 \\ 2010 & 2.01 & -11.88 & 0.92 \\ 2011 & 2.04 & -13.50 & 0.86 \\ 2012 & 2.21 & -13.54 & 0.80 \\ 2013 & 1.79 & -7.92 & 0.90 \\ 2014 & 1.68 & -7.98 & 0.82 \\ 2015 & 1.78 & -9.62 & 0.87 \\ & & & \end{array}$

For descending branch

$a_{2}$

$b_{2}$

$R_{2}^{2}$

0.94

$-1.57$

24.83

0.90

.88

$-1.94$

29.00

0.88

0.90

$-1.84$

29.38

0.89

0.89

$-1.57$

26.75

0.91

$-2.18$

32.40

0.93

0.94

$-2.16$

31.66

0.94

$-1.54$

25.87

0.90

$-1.46$

25.27

0.88

$-1.67$

28.33

0.90

$-1.58$

0.87

$-1.88$

27.70

0.92

$-1.76$

30.51

0.87

$-1.71$

29.09

0.91

$-1.77$

28.81

0.86

$-1.72$

30.55

0.90

$-1.92$

28.51

0.94

$-1.65$

31.44

0.90

$-1.76$

27.33

0.90

$-1.77$

0.90

An important aspect of the meteorological conditions is the amount of precipitation. For the characteristics of this indicator we applied their cumulative level on a decadal scale from the beginning of the year. Analysis of meteorological data for the period of research has allowed us to identify trends in variation of cumulative indicators of rainfall. We have reviewed the dynamic of the rainfall for the current year from the beginning of the year and for the last half of the previous year, the cumulative total since the beginning of the year (Fig. 4).

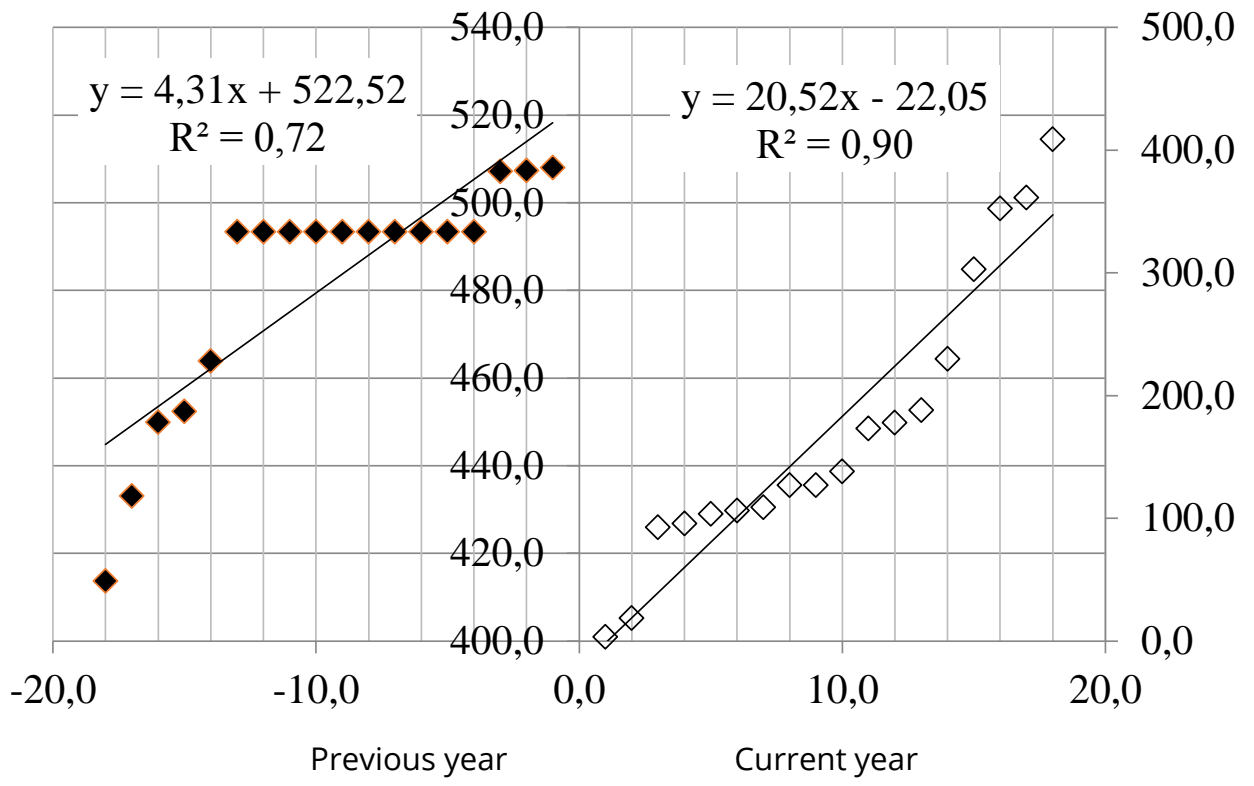

Fig. 4. A typical course of cumulative rainfall on decadal scale during the year (as the example, we show data for 2015). Horizontal axis is the order of decades from the beginning of the year, vertical axis is the cumulative rainfall for the decades, $\mathrm{mm}$. Straight lines indicate the trend of cumulative rainfall evaluated using linear approximation (see text)

The course of precipitation accumulation of a given year until the occurrence of the event (the start or end of spawning, spawning duration) and the course of precipitation accumulation of the previous year may probably have importance for explaining the timing of occurrence of the spawning events. The dependence of the indicator of 
cumulative precipitation (accumulative total precipitation on decadal scale including rain in this decade) on time is quite accurately described using a linear equation of the form:

$$
Y=b+a * X
$$

where $\mathrm{Y}$ is the cumulative precipitation on decadal scale; $\mathrm{X}$ - the order of decades within I-VI months of the year, $a$ and $b$ are regression parameters.

A similar equation can apply for the course of cumulative precipitation on decadal scale over the vil|-XII months of the previous year.

The parameters of the regression and coefficients of determination have the following ecological content. A parameter $a$ can be interpreted as the intensity of the rainfall during the relevant period. A parameter $b$ can be interpreted as the amount of rainfall at the beginning of the relevant period.

The linear model reflects the general trend of precipitation in the spring or fall of the previous year. In fact, the progress of the precipitation has the character of a complex vibrational process. Therefore the coefficient of determination of linear regression indicates the degree of conformity of a real process to linear model. Significant deviations from the overall trend lead to a reduction in the coefficient of determination. These deviations are a consequence of the ongoing processes of substantial loss of rainfall, which has alternated with periods of drought. The more frequent such phenomena, the smaller the coefficient of determination.

Thus, to describe the timing of spawning events we can explore the nature of the impact on them of such indicators, as the parameters of the regression model of dynamics of cumulative rainfall during the first half of a given year and the second half of the previous year (Table 3).

Table 3. The parameters of the regression models of cumulative rainfall course during the year

The parameters of the regression models

Year $\quad$ For the first half of the current year

$\begin{array}{lccc} & a_{1} & b_{1} & R^{2} \\ 1997 & 12.63 & -20.14 & 0.9 \\ 1998 & 13.36 & -15.20 & 0.97 \\ 1999 & 16.28 & 26.59 & 0.9 \\ 2000 & 18.73 & -26.01 & 0.9 \\ 2001 & 10.81 & -19.70 & 0.9 \\ 2002 & 10.12 & 48.06 & 0.9 \\ 2003 & 23.24 & 23.39 & 0.9 \\ 2004 & 15.80 & 10.87 & 0.93 \\ 2005 & 17.02 & -7.82 & 0.9 \\ 2006 & 6.87 & 24.25 & 0.88 \\ 2007 & 15.68 & -39.69 & 0.9 \\ 2008 & 16.10 & 17.95 & 0.95 \\ 2009 & 14.69 & 52.58 & 0.9 \\ 2010 & 11.29 & 5.27 & 0.92 \\ 2011 & 11.15 & 7.40 & 0.97 \\ 2012 & 10.57 & 39.85 & 0.94 \\ 2013 & 20.52 & -22.05 & 0.90 \\ 2014 & 20.52 & -22.05 & 0.90 \\ 2015 & 12.63 & -20.14 & 0.9\end{array}$

The parameters of the regression models of temperatures and precipitation courses are characterized by significant levels of inter-correlation that make them multicollinear predictors, which leads to uncertainty of parameters of regression models based on them. If environmental predictors are correlated, then it is inherently difficult to tease apart their effects. Principal component analysis can be used for dimensionality reduction and to move to new orthogonal nonmulticollinear variables (Table 4). The first five principal components have eigenvalues exceeding 1 , which together explain $82.55 \%$ of total variance. The principal component 1 is strongly correlated with such of the original variables as temperature course of the previous year, variability in temperature and rainfall rate in the given year and the overall level of rainfall in the first half of the previous year. The principal component 2 reflects the dynamic of the temperature conditions in the given (current) year, the temperature conditions the previous summer and rainfall in winter. The principal component 3 is the most sensitive to temperature variability in the second half of the previous year, the intensity of rainfall in the current and previous years. This component is sensitive to this aspect of the relationship, when 
Bondarev, D. et al. Assessment of the impact of seasonal patterns climatic.... Acta Biologica Sibirica, 2018, 4(2), 61-77

intense precipitation at the end of the year is followed by moderately lower precipitation in the spring of next year and vice versa. The principal component 4 indicates the variability of temperature regime during the current and previous years, and the dynamics of rainfall of the current year. The principal component 5 is strongly correlated with rainfall variability in the previous year.

Table 4. Principal Component Analysis of meteorological parameters (presenting only statistically significant correlation coefficients with $p<0.05$ )

\begin{tabular}{lllcrl}
\hline \multirow{2}{*}{ Parameters of regression models } & \multicolumn{4}{c}{ Principal Components } \\
& PC1 & PC2 & PC3 & PC4 & PC5
\end{tabular}

Temperature course. Ascending branch of year when spawning occurred

\begin{tabular}{|c|c|c|c|c|c|}
\hline$a_{1}$ & - & -0.96 & - & - & - \\
\hline$b_{1}$ & - & 0.96 & - & - & - \\
\hline$R_{1}^{2}$ & -0.65 & - & - & -0.54 & - \\
\hline \multicolumn{6}{|c|}{ Temperature course. Descending branch of the previous year } \\
\hline$a_{2}$ & 0.94 & - & - & - & - \\
\hline$b_{2}$ & -0.94 & -0.25 & - & - & - \\
\hline$R_{2}^{2}$ & -0.28 & - & 0.76 & -0.34 & - \\
\hline \multicolumn{6}{|c|}{ Cumulative precipitation. Current year } \\
\hline$a w_{1}$ & 0.42 & - & -0.42 & -0.39 & - \\
\hline$b w_{1}$ & - & -0.34 & - & 0.51 & 0.46 \\
\hline$R W^{2}{ }_{1}$ & - & - & - & -0.83 & - \\
\hline \multicolumn{6}{|c|}{ Cumulative precipitation. Previous year } \\
\hline$a w_{2}$ & - & - & 0.79 & - & 0.40 \\
\hline$b w_{2}$ & 0.62 & - & - & - & -0.63 \\
\hline$R w_{2}^{2}$ & - & - & - & - & 0.95 \\
\hline \multicolumn{6}{|c|}{ Principal Components statistics } \\
\hline Eigenvalue & 3.63 & 2.17 & 1.80 & 1.20 & 1.10 \\
\hline$\%$ Total variance & 30.22 & 18.12 & 15.00 & 10.00 & 9.21 \\
\hline $\begin{array}{l}\text { Cumulative } \% \text { of } \\
\text { total variance }\end{array}$ & 30.22 & 48.34 & 63.34 & 73.34 & 82.55 \\
\hline
\end{tabular}

The principal components are useful for drawing statistically reliable conclusions about white bream spawning. General linear models are able to explain $42-90 \%$ of variability in the timing of white bream spawning (Table 5).

Table 5. General linear models of the dependence of timing of Blicca bjoerkna spawning on climatic factors (presenting only statistically significant regression coefficients with $p<0.05$ )

Time of the spawning

$$
\text { Predictors }
$$

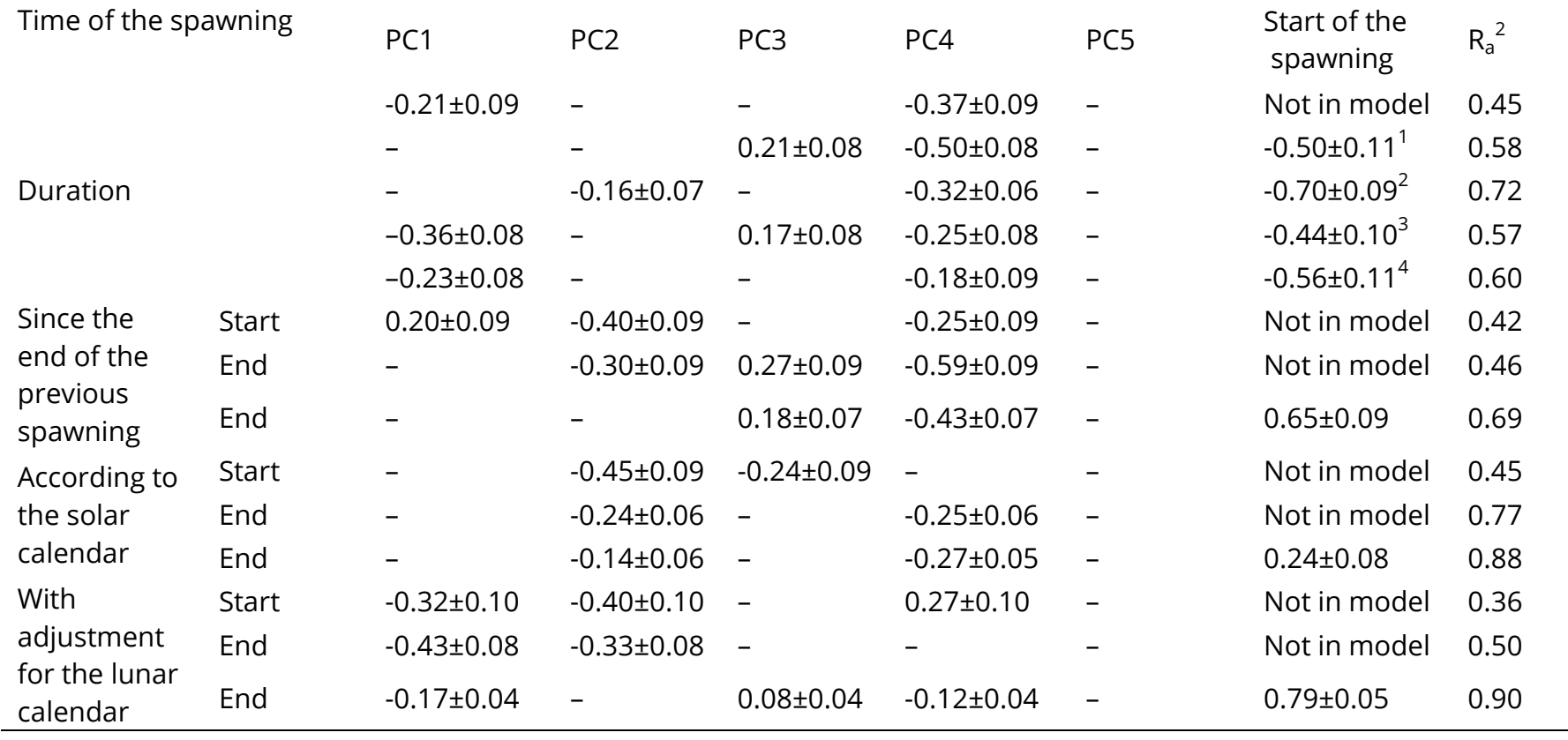


Bondarev, D. et al. Assessment of the impact of seasonal patterns climatic... Acta Biologica Sibirica, 2018, 4(2), 61-77

$\begin{array}{llllllll}\text { With } & \text { Start } & - & -0.39 \pm 0.08 & -0.33 \pm 0.08 & 0.35 \pm 0.08 & 0.20 \pm 0.08 & \text { Not in model } 0.52 \\ \begin{array}{l}\text { adjustment } \\ \text { for the }\end{array} & \text { End } & -0.26 \pm 0.07 & - & -0.24 \pm 0.07 & - & \text { Not in model } & 0.65 \\ \begin{array}{l}\text { semilunar } \\ \text { calendar }\end{array} & \text { End } & -0.24 \pm 0.06 & - & - & -0.17 \pm 0.06 & - & 0.52 \pm 0.09 \\ \end{array}$

Legend: ${ }^{1}$ - since the end of the previous spawning; ${ }^{2}$ - according to the solar calendar; ${ }^{3}$ - with adjustment for the lunar calendar; ${ }^{4}$ - with adjustment for the semilunar calendar.

The general linear model with principal components as predictors can explain $45 \%$ of the variability of white bream spawning duration. The duration of spawning depends on the principal components 1 and 4 . Taking into account the timing of the beginning of spawning can greatly improve the prognostic properties of the regression model. The regression coefficients for the timing of the beginning of the spawning season are always negative, indicating that than later the spawning begins, the faster it takes place. The largest share of variability of duration of spawning is explained by the model with the use of the solar time for the measurement of the beginning of the spawning season. A common feature for all models is the presence as statistically probable predictor of main component 4. Other potential predictors of the models are different.

Using climatic factors can explain $45 \%$ of the variability of beginning of white bream spawning according to the solar calendar. Statistically likely predictors are main components 2 and 3 . The timing of the end of the spawning is to a greater extent dependent on climatic factors, as their use can describe $77 \%$ of the variability of these signs. The end of spawning depends on components 2 and 4. Taking into account the period of the beginning of the spawning season greatly improves the predictive properties of the model that can explain the $88 \%$ of the variability of the end of spawning.

The accuracy of the explanation of the variability of early spawning by counting from the end of previous spawning is almost indistinguishable from similar models for the solar calendar. The difference is the other method of counting statistically probable predictors. Variation in the timing of the end of the spawning season, estimated by counting from the end of the last spawning, is explained more poorly using climatic factors. Taking into account the start of spawning is not such an effective model as the model using the solar calendar.

The model that describes the variation of the end of the spawning period with measurement of time of its beginning with corrections according to the lunar calendar has the best explanatory ability - $90 \%$. Within this model, the greatest contribution is the data about the timing of the onset of spawning.

Biotopes are statistically probable predictors in all models. The character of biotopic distribution of timing of the onset of spawning is similar in all methods of assessment of timing, so we present results only for the solar calendar (Fig. 5).

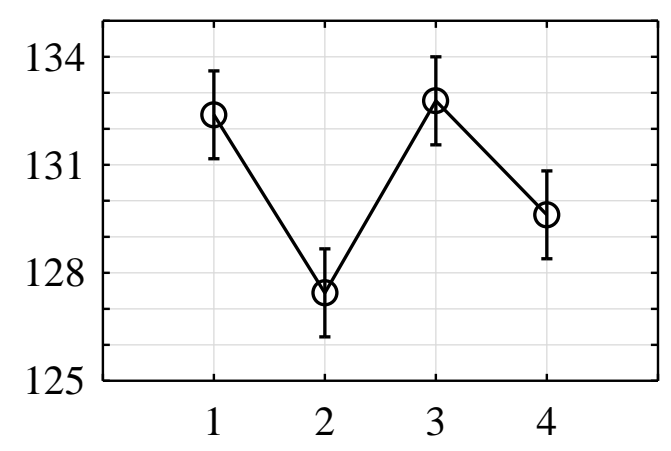

Start of spawning

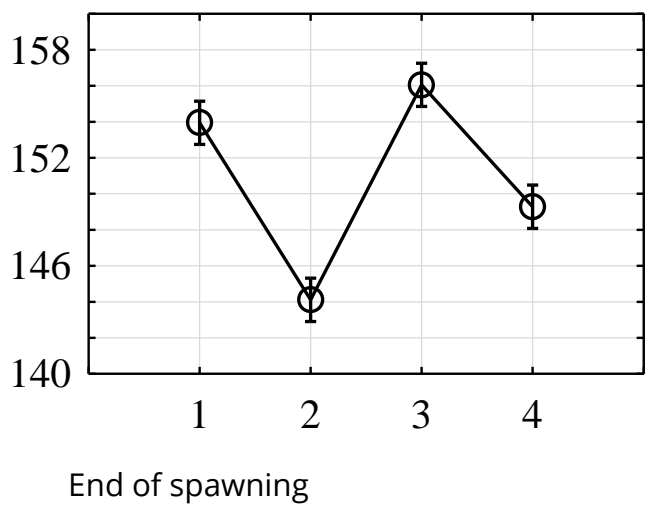

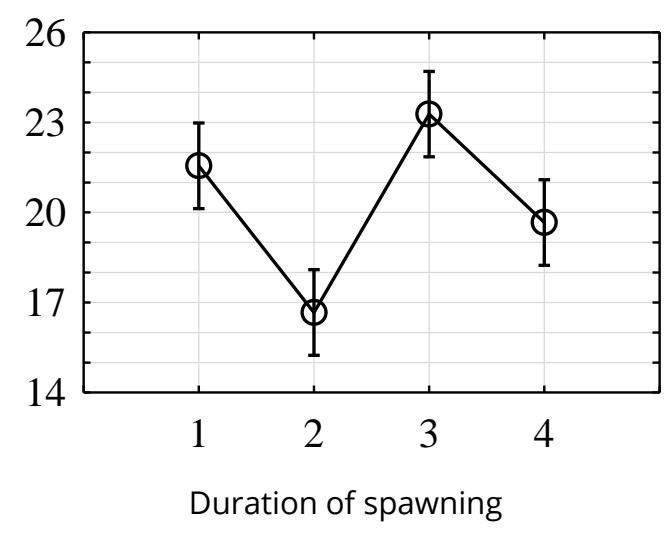

Fig. 5. Dependence of timing of Blicca bjoerkna spawning on habitat 
Legend: rings are the mean, days after January 1 of each year for start and end of spawning and days of the duration of spawning, vertical bars are 95\% confidence interval; 1 - Nikolayev ponds system ledge; 2 - River Protoch system and Obukhov floodplain; 3 - The channel of the River Dnipro; 4 - Ponds of the Taromske ledge.

The earliest spawning occurs in the River Protoch system and Obukhov floodplain. This biotope has the shortest spawning duration. Then spawning occurs in the waters of the Taromske ledge, then almost simultaneously in waters of the Nikolayev ledge and the channel of the River Dnipro. The duration of spawning is greatest in the River Dnipro.

\section{Discussion}

The timing and places of the fish spawning are adaptations to defense against enemies and to providing young with food (Nikolsky, 1974). The reproductive cycle of cyprinidae fishes is mainly regulated by temperature (Billard et al. 1978). Temperature is a fundamental physical regulatory factor in the life of fishes and this effect manifests itself particularly strongly in control of all reproductive processes from gamete development and maturation, ovulation and spermation, spawning, embryogenesis, hatching, to larval and juvenile development and survival (Pankhurst \& Munday, 2011). For reproductively mature adults, temperatures are generally considered as a secondary stimulus to photoperiodicity in the formation of phases of the reproductive cycle, but has a prominent role in synchronizing the final stages of reproductive maturity (Pankhurst \& Porter, 2003). Seasonal variability in temperature and rainfall are important factors in the survival and reproduction of fish (Kanno et al., 2015).

Our results indicate that in the reserve white bream begin to spawn in floodplain waters at the water temperature of $14-15^{\circ} \mathrm{C}$. In other parts of its range spawning is also observed at temperatures higher than $15^{\circ} \mathrm{C}$ (Kottelat \& Freyhof, 2007). In most cases, spawning is mass and occurs in the shore zone. Spawning takes place on submerged aquatic vegetation. It is often possible to fix spawning visually. Usually in waters of the reserve, white bream spawn twice a year (first spawning takes place in May or early June, as an exception to the last days of April, and the second is in late June or early July). In other parts of its range, white bream lay eggs in two or three stages (Tadajewska, 2000). It should be noted that the data obtained during the study allow us to reliably evaluate only the first spawning. The earliest term of the start of spawning during our research was noted in 1997 (April 29). The latest start of spawning was observed in 2006 (17-23 May).

Obviously, the phenomenon of the spawning is defined not only in terms of the relevant period, but also by the physiological state of the fish, which in turn depends on the availability of trophic resources and climate regime throughout the period from the end of the previous spawning. To address the issue of search for relationship between timing of the spawning and climate regime, the important question is to quantify the dynamics of climatic conditions. Dynamics of climatic conditions are characterized by a time series of corresponding indicators, in this case being temperature and precipitation. The temperature in scale of seasonal changes correlates well with the temperature of water in the reservoirs (Stefan \& Preud'homme, 1993; Mohseni \& Stefan, 1999). Precipitation affects the water regime of the water bodies and the chemistry of the water in them (Ye \& Grimm, 2013; Jha et al., 2015).

The overall long-term trend of ten day temperature changes has a clear sinusoidal dependence. But the course of temperature increase during spring or reduction during autumn can be accurately approximated by a linear model. Parameters of linear models for each year are quite good markers of the specific climatic conditions that are used as predictors in the regression model to explain the timing of the onset and duration of spawning. In addition, the content of these parameters can be meaningfully interpreted, which helps to explain the obtained models. The model parameters reflect the following aspects of the dynamics of climate conditions, both coldness of winter and summer heat, the rate of warming in the spring or cooling in autumn and degree of instability of warming or cooling trends.

In the steppe zone of Ukraine rainfall occurs sporadically. Significant periods without rain are common and occur at different times and for varying durations. Therefore, for modeling, the best solution is to use cumulative rainfall estimates. This index increases steadily over time and can be described via continuous functions. We used linear model parameters as predictors and coefficient of determination $R^{2}$, which indicates the level of correspondence of the observed data to linear model.

The parameters of regression models of the temperature and precipitation dynamics are highly correlated, so before applying them within the framework of the general linear model of the influence of climatic factors on the timing of spawning of white bream they were subjected to principal components analysis. This approach allowed us to distinguish five principal components. The principal component 1 (PC 1) is most sensitive to progress of temperature course of the previous year, the principal component 2 (PC 2) is mainly sensitive to the temperature course of the current year, the principal component 3 (PC 3) indicates an inverse correlation between the intensity of rainfall in current and previous years, the principal component 4 (PC 4) is sensitive to the dynamics of rainfall in the current year, the principal component 5 (PC 5) presents the dynamics of rainfall last year.

The start of the spawning is recorded in earlier periods in a period of unstable weather conditions which varies according to the temperature indicators. Its course is characterized by considerable dependence on the environmental conditions. In the event of a significant cooling, spawning may be interrupted. For the most part, the number of males on the breeding grounds is negligible. In addition, its duration is significantly reduced and the phenological date of its onset is practically the same for various habitats. In contrast, spawning that occurs during a "late" spring is characterized by the later period of its beginning. There are significant concentrations of males on the breeding grounds. The spawning 
Bondarev, D. et al. Assessment of the impact of seasonal patterns climatic... Acta Biologica Sibirica, 2018, 4(2), 61-77

duration is significantly extended in time. Phenological dates of its start and end in different habitats of the reserve vary considerably over time.

Biotopes are characterized by statistically significant features in terms of beginning and duration of spawning. Flood plain areas (Obukhov ponds and the Taromske ledge) and the Orel estuary are characterized by weak flowage and general shallowness. That is why spawning occurs earlier and is brief in duration. Within other parts of the waters of the reserve characterized by significant flowage and there are more limited shallow sites suitable for spawning, the onset of white bream spawning occurs later. Its duration is greater, and the dependence on temperature factors is expressed to a greater extent than floodplain areas. Obviously, the temperature variation is refracted through water features in specific temperature conditions of each water body. Of course, not only the specificity of physical conditions but biotic features influence the course of the white bream spawning process.

An important aspect of the study of the natural processes dynamics is the timing of processes. An anthropocentric approach often dictates the use of the usual astronomical timepiece for man, namely solar, which corresponds to the calendar method of measuring time and phenological events. The alternative could be another astronomical or biological time. Solar time, namely the beginning of a new year can be adjusted in view of the monthly cycle of events. We started the countdown is not on January 1 of each year, but with the onset of the first new moon after January 1 of each year. We applied a correction based on the semilunar cycle, the countdown began with the new moon or the full moon.

Alternative to astronomical time is biological time, or the time between biological events. In our case, this is the time from the end of the spawning season in the previous year to the beginning of the spawning season in a current year. A marker of biological time is also the time of spawning in any dimension, if this parameter is used in the models as the predictor.

The "invariant representation" in the method of measuring time is the duration of spawning. The duration of spawning varies depending on the course of the temperatures in the previous year, drastic changes in temperature in the spring of the current and the intensity of precipitation during the previous year (PC 1) and cumulative rainfall for the current year (PC 4) Adding as a predictor the time of onset of spawning significantly improves the explanatory power of the model regardless of the method of measuring time. The largest increase happens in models in which the measurement is by solar astronomical time. A common feature for all models is the high predictive capacity of PC 4 which presents dynamics of rainfall in a current year and instability in the course of temperatures in the current and previous year. If during the spring and previous autumn periods of warming are interrupted by cooling, then this increases the duration of spawning. Typically, this coincides with years with an increased level of precipitation in the spring.

The variability of the time between the end of the previous spawning and spawning events in a current year can be explained using climate metrics (42-69\%). For all models, an important role is played by PC 4 . To predict the start of spawning, the course of temperatures of the previous year (PC 1) and the current year (PC 2) are also important and for the end of the spawning, the course of temperatures of the current year (PC 2) and redistribution of precipitation between the current and previous years (PC 3) (or just PC 3 taking into account the timing of the beginning of the spawning season). Thus "the biological time" of the reference period of spawning is sensitive to climatic events for an entire year from the end of the previous spawning to the spawning in the current year.

Duration of time estimation by the astronomical calendar is two times less than by biological calendar, but the accuracy of the predicted values for the climatic predictors is not much better, $45-88 \%$ for the solar calendar. The model for the start of spawning by the solar calendar, unlike the vast majority of the other models, does not contain PC 4 as a statistically significant predictor. The start of spawning by the solar calendar is determined by PC 2 and PC 3 . For the end of the spawning season markers of the climatic conditions of the current year (PC 2 and PC 4) are important. Among them there are also indicators of temperature in winter. The phenology of fish spawning is disturbed by conditions of short and warm winters (Farmer et al., 2015). Reduction in the duration of the winter leads to the fact that the female do not spawn at the usual temperatures for the species (Hokanson, 1977; Collingsworth \& Marschall, 2011). In years with early spring, spawning can occur in later than the point when the temperature reaches the optimal value for spawning, but at more usual times for spawning (Farmer et al., 2015). Thus, measurements of astronomical time according to the solar calendar indicate aspects of variation in the duration of spawning, which is the most sensitive to the varying climatic conditions in the year of spawning.

The model with adjustment according to the lunar calendar places more emphasis on variability of climatic conditions described by PC 1 - the course of temperature in the previous year and variation in temperature and intensity of rainfall in the current year. It can be assumed that the lunar cycles correct the rhythm of natural processes, which gives rise to certain sequences of climatic rhythms. Lunar rhythms acting as "proximate causes" (Baker, 1938) and set up a rhythm of spawning based on a dynamic of climate change.

The statistical distribution of the spawning period according to the lunar calendar is clearly bimodal, which allows us to suggest the presence of a semilunar rhythm of spawning events. The distribution of assessments of the time of spawning with adjustment for the semilunar period is really unimodal and with a positive excess that indicates the tendency in the duration of spawning towards a certain modal value according to the semilunar calendar. It should be noted that the only model assessing time taking into account the semilunar cycle has PC5 (rhythm of precipitation of the previous year) as a statistically significant predictor.

Thus, the analysis of existing phenology data and results enables us to adequately assess the environmental features of the course of white bream spawning in the waters of the reserve. We discovered the dependence of the 
Bondarev, D. et al. Assessment of the impact of seasonal patterns climatic... Acta Biologica Sibirica, 2018, 4(2), 61-77

period of onset, total duration and end of spawning on the existing natural conditions, especially the influence of temperature factors. The results obtained in the future may have significant value for the overall assessment of effectiveness of natural reproduction of white bream in terms of existing climate change.

White bream spawning is a function of the complex of ecological processes that are driven by the course of climatic conditions during a shorter period of the year. The results obtained indicate that the population system of the fish has a memory regarding annual dynamics of climatic conditions. This memory has the character of storage of certain changes. On achieving a critical state, the system reacts through an important event in the life cycle of fish - spawning. Global warming is expressed as an upward shift of temperature curves. It should be noted that the cumulative response of biological systems smoothens these trends. Of course, there is a possibility that changes in the phenology of spawning could lead to desynchronization with the development of plankton and cascading effects on the food chains, which may have consequences for the entire ecosystem (Blenckner, 2001; Edwards \& Richardson, 2004). But the fact that the timing of the onset of spawning is a function of both abiotic and biotic components indicates that the most likely scenario remains changes of a synchronous character due to the variation of temperature. Of course, this applies to a certain level of global warming.

\section{Conclusion}

The spawning phenology of the white bream Blicca bjoerkna (Linnaeus, 1758) depends on the dynamics of weather conditions over time. Patterns of varying climatic regimes that are expressed by means of multivariate principal components are the most informative predictors of the spawning events. Evaluation of the onset of spawning events in astronomical and biological time gives somewhat different models of the impact of climate regimes. A constant component of almost all models is the statistically probable influence of the principal components, indicating the variability of rainfall during the year in which spawning occurs. Models using the solar calendar are the most sensitive to temperature conditions of the current year. Correction of time based on the lunar cycle assesses developments which are sensitive also to the varying temperature and rainfall rhythm during the second half of the previous year. Biological time is sensitive to environmental influences over the period from the end of spawning in the previous year to spawning in the current year.

\section{References}

Alavi, S.M.H. \& Cosson, J. (2005) Sperm motility in fishes. I. Effects of temperature and pH: A review. Cell Biology International, 29 (2), 101-110. DOI: 10.1016/j.cellbi.2004.11.021

Arsan, O.M., Davydov, O.A. \& D'yachenko, T.M. (2006). Methods of hydroecological researches of surface water. Logos, Kiev (in Ukranian with English summary).

Baker, J.R. (1938). The evolution of breeding seasons. In: de Beer G.R. (ed), Evolution: Essays on Aspects of Evolutionary Biology. Clarendon Press, Oxford, UK: 161-177.

Beklemishev, V.N. (1928). Organism and Community (To the Problem of Individuality in Biocoenology). Tr. Biol. nauch.issled. in-ta i Biol. st. pri Permskom univ. 1(2-3), 12-14 (in Russian).

Beklioglu, M., Meerfhoff, M., Søndergaard, M. \& Jeppesen, E. (2011). Eutrophication and restoration of shallow lakes from a cold temperate to a warm mediterranean and a (sub) tropical climate. In: A.A. Ansari, G.R. Lanza, S.S. Gill \& W. Rast (eds), Eutrophication: Causes, Consequences and Control. Springer, New York, 91-108.

Berg, L.S. (1949). Fishes of fresh waters of the USSR and adjacent countries. Part 2. Izdatel'stvo Akademii Nauk SSSR, Moscow-Leningrad (in Russian).

Billard, R., Breton, B., Fostier, A., Jalabert, B. \& Weil, C. (1978) Endocrine control of the teleos reproductive cycle and its relation to external factors: salmonid and cyprinid models. In: P. J. Gaillard, H. H. Boer (eds), Comparative Endocrinology. Elsevier/North Holland Biomedical Press, Amsterdam, 37-47.

Billard, R. (1986). Spermatogenesis and spermatology of some teleost fish species. Reproduction Nutrition Développement 26 (4), 877-920. DOI: 10.1051/rnd:19860601

Blenckner, T. (2001). Climate Related Impacts on a Lake. From Physics to Biology. Acta Universitatis Upsaliensis. Comprehensive Summaries of Uppsala Dissertations from the Faculty of Science and Technology, 674, 37.

Bondarev, D. L. \& Zhukov, O. V. (2017) Phenology of the white bream (Blicca bjoerkna) spawning in natural reserve "Dnieper-Orylskiy" in dependence from seasonal temperature dynamic. Biosystems Diversity, 25(2), 67-73. doi:10.15421/011710

Bondaryev, D. L. (2007). The structure of the spawning populations of bream (Abramis brama) of the Dnieper-Oril Nature Reserve. Visnyk Dnipropetrovs'koho universytetu. Biolohiya. Ekolohiya, 15(1), 9-14 (in Russian with English summary).

Bradshaw, W.E. \& Holzapfel, C.M. (2007). Evolution of animal photoperiodism. Annu. Rev. Ecol. Evol. Syst., 38, 1 -25. doi:10.1146/annurev.ecolsys.37.091305. 110115

Bradshaw, W.E. \& Holzapfel, C.M. (2010). Light, time, and the physiology of biotic response to rapid climate change in animals. Annu. Rev. Physiol., 72, 149-166. (doi:10.1146/annurev-physiol-021909-135837)

Breton, B., Horoszewicz, L., Billard, R. \& Bieniarz, K. (1980). Temperature and reproduction in tench: Effect of a rise in the annual temperature regime on gonadotropin level, gametogenesis and spawning. I. The male. Reproduction Nutrition Développement, 20 (1A), 105-118. DOI: 10.1051/rnd:19800106 
Bondarev, D. et al. Assessment of the impact of seasonal patterns climatic... Acta Biologica Sibirica, 2018, 4(2), 61-77

Brett, J.R. (1979). Environmental factors and growth. In: Hoar W.S., Randall D.J. \& Brett J.R. (eds.) Fish physiology. Vol. 8. Bioenergetics and growth. Academic Press, NewYork, NY, USA: 599-675.

Chugunova, I. I. (1952). Methods of studying the age and growth of fish. AN SSSR, Moscow (in Russian).

Collingsworth, P. D. \& Marschall, E. A. (2011). Identifying relationships between catches of spawning condition yellow perch and environmental variables in the western basin of Lake Erie. Trans. Am. Fish. Soc. 140, 31-36.

Crozier, L. G. \& Hutchings, J. A. (2014). Plastic and evolutionary responses to climate change in fish. Evolutionary Applications, 7, 68-87.

Domagała, J., Kirczuk, L. \& Pilecka-Rapacz, M. (2013). Annual development cycle of gonads of Eurasian ruffe (Gymnocephalus cernuus L.) females from lower Odra River sections differing in the influence of cooling water. Journal of Freshwater Ecology, 28(3), 423-437. DOI: 10.1080/02705060.2013.777855

Domagała, J., Kirczuk, L. \& Pilecka-Rapacz, M. (2015). Annual development cycle of gonads of bream (Abramis brama L. 1758) females from lower Oder river sections influenced differently by the heated effluents from a power station. Journal of Applied Ichthyology, 31 (Suppl. 1): 41-48. DOI: 10.1111/jai.12723

Domagała, J., Dziewulska, K., Kirczuk, L. \& Pilecka-Rapacz, M. (2015). Sexual cycle of white bream, Blicca bjoerkna (Actinopterygii, Cypriniformes, Cyprinidae), from three sites of the lower Oder River (NW Poland) differing in temperature regimes. Acta Ichthyol. Piscat., 45 (3), 285-298.

Edwards, M. \& Richardson, A.J. (2004). Impact of climate change on marine pelagic phenology and trophic mismatch. Nature, 430, 881-884.

Farmer, T.M., Marschall, E.A., Dabrowski, K. \& Ludsin, S.A. (2015). Short winters threaten temperate fish populations. Nature Communications, 6, 7724. DOI: 10.1038/ncomms8724

Fischer, J. H., Freake, M. J., Borland, S. C. \& Phillips, J. B. (2001). Evidence for the use of magnetic map information by an amphibian. Animal Behaviour, 62, 1-10.

Forrest, J. \& Miller-Rushing, A.J. (2010). Toward a synthetic understanding of the role of phenology in ecology and evolution. Phil. Trans. R. Soc. B365, 3101-3112. (doi:10.1098/rstb.2010.0145)

Foster, R.G. \& Kreitzman, L. (2009). Seasons of life: the biological rhythms that enable living things to thrive and survive. Yale University Press, New Haven, CT.

Grant, R. A., Chadwick, E. A. \& Halliday, T. (2009). The lunar cycle: a cue for amphibian reproductive phenology? Animal Behaviour, 78 (2), 349-357.

Günther, B. \& Morgado, E. (2004). Time in physics and biology. Biol. Res. 37 (4), A: 759-765. dx.doi.org/10.4067/S071697602004000500005

Gwinner, E. (1981). Annual Rhythms: Perspective. In: Aschoff J. (eds) Biological Rhythms. Springer, Boston, MA: 381-389. doi.org/10.1007/978-1-4615-6552-9_20

Hacker, R. (1979). Fishes and fishery in Neusiedlersee. In: Löffler H. (ed.) Neusiedlersee: The limnology of a shallow lake in Central Europe. Dr. W. Junk Publishers, The Hague, Boston, London, 423-438. DOI: 10.1007/978-94-009-9168-2

Helm, B., Ben-Shlomo, R., Sheriff, M.J., Hut, R.A. Foster, R., Barnes, B.M. \& Dominoni, D. (2013). Annual rhythms that underlie phenology: biological time-keeping meets environmental change. Proc $R$ Soc B, 280, 20130016. http://dx.doi.org/10.1098/rspb.2013.0016

Herzig, A. \& Winkler, H. (1986). The influence of temperature on the embryonic development of three cyprinid fishes, Abramis brama, Chalcalburnus chalcoides mento and Vimba vimba. Journal of Fish Biology, 28 (2), 171-181.

Hokanson, K. E. F. (1977) Temperature requirements of some percids and adaptations to seasonal temperature cycle. J. Fish. Res. Board Can., 34, 1524-1550.

Immelmann, K. (1971). Erörterungen zur Definition und Anwendbarkeit der Begriffe 'ultimate factor', 'proximate factor' und 'zeitgeber' [Definition and use of the terms "ultimate factor", "proximate factor" and "zeitgeber"]. Oecologia, 9, 259264. (doi:10.1007/BF00345235)

Jafri, S.I.H. (1989). The effects of photoperiod and temperature manipulation on reproduction in the roach Rutilus rutilus (L.) (Teleostei). Pakistan Journal of Zoology, 21 (4), 289-299.

Jha, M.K., Gassman, P.W. \& Panagopoulos, Y. (2015). Regional changes in nitrate loadings in the Upper Mississippi River Basin under predicted mid-century climate. Reg. Environ. Chang., 15, 449-460.

Jobling, M. (2003). The thermal growth coefficient (TGC) model of fish growth: A cautionary note. Aquaculture Research, 34(7), 581-584. DOI: 10.1046/j.1365-2109.2003.00859.x

Kanno, Y., Letcher, B.H., Hitt ,N.P., Boughton, D.A., Wofford, J.E.B. \& Zipkin, E.F. (2015). Seasonal weather patterns drive population vital rates and persistence in a stream fish. Glob. Chang. Biol., 21, 1856-1870.

Koblitskaya, A. F. (1963). Study of the spawning of freshwater fish. Pishevaya promishlenost, Moscow (in Russian).

Koli, L. (1990). Fishes of Finland. Werner Söderström Osakeyhtiö, Helsinki (In Finnish).

Kompowski, A. \& Neja, Z. (1999). The Międzyodrze ichthyofauna as caught by various gear. Baltic Coastal Zone, 3, 103112.

Kopiejewska, W. (1996). Germ line of white bream, Blicca bjoerkna (L.) females in Włocławek Reservoir. Acta Ichthyologica et Piscatoria, 26 (2), 35-47.

Kopiejewska, W. \& Kozłowski, J. (2007). Development structure of ovaries in female white bream, Abramis bjoerkna from Lake Kortowskie in north-eastern Poland. Folia Zoologica, 56 (1), 90-96. 
Bondarev, D. et al. Assessment of the impact of seasonal patterns climatic... Acta Biologica Sibirica, 2018, 4(2), 61-77

Kottelat, M. \& Freyhof, J. (2007). Handbook of European Freshwater Fishes. Cornol (Switzerland) and Berlin (Germany). Published by the authors.

Kryizhanovskiy, S. G. (1949). Ecological and morphological patterns of development cirque, loaches and catfish fish. Tr.in-ta morfologii zhivotnyih AN SSSR, 1, 5-332 (in Russian).

Lahnsteiner, F. \& Mansour, N. (2012). The effect of temperature on sperm motility and enzymatic activity in brown trout Salmo trutta, burbot Lota lota and grayling Thymallus thymallus. Journal of Fish Biology, 81 (1), 197-209. DOI: 10.1111/j.1095-8649.2012.03323.x

Lohmann, K. J. \& Willows, A. O. D. (1987). Lunar-modulated geomagnetic orientation by a marine mollusk. Science, 235, 331-334.

Lyubishchev, A. A. (1982). Problems of Taxonomy and Evolution of Organisms. Collection of Papers. Nauka, Moscow (in Russian).

Mann, R.H.K., Mills, C.A. \& Crisp, D.T. (1984). Geographical variation in the life-history tactics of some species of freshwater fish. In: Potts G.W., Wootton R.J. (eds.) Fish reproduction: Strategies and tactics. Academic Press, London, UK, 171186.

Mbungu, W., Ntegeka, V., Kahimba, F.C., Taye, M. \& Willems, P. (2012). Temporal and spatial variations in hydroclimatic extremes in the Lake Victoria basin. Phys. Chem. Earth, 50-52, 24-33.

McCarty, J. (2001). Ecological consequences of recent climate change. Conserv Biol., 15, 320-331.

McDowall, R.M. (1969). Lunar Rhythms in Aquatic Animals A General Review. Tuatara, 17 (3), $133-143$.

Mikhailovsky, G. E. (1995). Biological time, its organization, hierarchy and presentation by complex values. In Levich A.P. (eds). On the Way to Understanding the Time Phenomenon, 68-84. doi.org/10.1142/9789812832092_0006

Mohseni, O. \& Stefan H.G. (1999). Stream temperature/air temperature relationship: a physical interpretation. J. Hydrol., 218, 128-141.

Molls, F. (1999). New insights into the migration and habitat use by bream and white bream in the floodplain of the River Rhine. Journal of Fish Biology, 55 (6), 1187-1200. DOI: 10.1111/j.1095-8649.1999.tb02069.x

NCADAC (2013). National climate assessment and development advisory committee. Third national climate assessment draft report: U.S. global change research program. http://www.globalchange.gov/publications/reports (accessed on Dec 2017).

Nikolskiy, G. V. (1974). Fish ecology. Vyisshaya shkola, Moscow (in Russian).

Noges, P. \& Jarvet, A. (2005). Climate driven changes in the spawning of roach (Rutilus rutilus (L.)) and bream (Abramis brama (L.)) in the Estonian part of the Narva River basin. Boreal Environment Research, 10 (1), 45-55.

Okgerman, H.C., Elp, M. \& Atasagun, S. (2012). The growth and reproduction of white bream (Blicca bjoerkna L. 1758) in an oligo-mesotrophic lake in northwest Anatolia (Sapanca, Turkey). Turkish Journal of Biology, 36 (1): 125-134. DOI: 10.3906/biy-1012-157

Ouarda, T.B.M.J., Charron, C., Kumar, K.N., Marpu, P.R., Ghedira, H., Molini, A., Kayal, I. (2014). Evolution of the rainfall regime in the United Arab Emirates. J. Hydrol., 514, 258-270.

Pankhurst, N. W. \& Porter, M. J. R. (2003). Cold and dark or warm and light: variations on the theme of environmental control of reproduction. Fish Physiology and Biochemistry, 28, 385-389. doi:10.1023/B:FISH. 0000030602.51939.50

Pankhurst, N. W. \& Munday, Ph. L. (2011). Effects of climate change on fish reproduction and early life history stages. Marine and Freshwater Research, 62, 1015-1026.

Pervukhin, M.A. (1979). Genetic classification of floodplain lakes. Moscow State University Press, Moscow (in Russian).

Phillips, J. B. (1986). Magnetic compass orientation in the eastern red-spotted newt (Notophthalmus viridescens). Journal of Comparative Physiology, A (158), 103-109.

Pravdin, I. F. (1966). Guide to the study of fish. Pischevaya prom-t, Moscow (in Russian).

Prejs, A., Martyniak, A., Boroń, S., Hliwa, P. \& Koperski, P. (1994). Food web manipulation in a small, eutrophic Lake Wirbel, Poland: Effect of stocking with juvenile pike on planktivorous fish. Hydrobiologia, 275(1), 65-70. doi: 10.1007/BF00026700

Rinchard, J. \& Kestemont, P. (1996). Comparative study of reproductive biology in single- and multispawner cyprinid fish. I. Morphological and histological features. Journal of Fish Biology, 49(5), 883-894. DOI: 10.1111/j.10958649.1996.tb00087.x

Rinchard, J. \& Kestemont, P. (2003). Liver changes related to oocyte growth in roach, a single spawner fi sh, and in bleak and white bream, two multiple spawner fish. International Review of Hydrobiology, 88(1), 68-76. DOI: 10.1002/iroh.200390006

Sandström, O., Neuman, E. \& Thoresson, G. (1995). Effect of temperature on life history variables in perch. Journal of Fish Biology, 47(4), 652-670. DOI: 10.1111/j.1095-8649.1995.tb01932.x

Schneider, K. N., Newman, R. M., Card, V., Weisberg, S. \& Pereira, D. L. (2010). Timing of walleye spawning as an indicator of climate change. Transactions of the American Fisheries Society, 139, 1198-1210.

Sharamok, T., Ananieva, T. \& Fedonenko, O. (2017). Environmental status of Kam'yanske reservoir (Ukraine). Ekológia (Bratislava), 36(3), 281-289.

Slastenenko, E. (1956). The Fishes of the Black Sea Basin. The General Directorate of Meat and Fish Publications (in Turkish). 
Sokolov, B. S. (2010). The Biosphere as a Biogeomeride and Its Biotope. Stratigraphy and Geological Correlation 18 (3): 229-233. DOI https://doi.org/10.1134/S0869593810030019

Spivak, E.G. (1987). Reproduction of the white bream Blicca bjoerkna (L.) in Kahovsk Reservoir bays. Voprosy Ihtiologii, 27(1), 101-105 (in Russian).

Spratte, S. \& Hartmann, U. (1997). Fischartenkataster: Suswasserfische und Neunaugen in Schleswig-Holstein. Ministerium für landliche Raume, Landwirtschaft, Ernahrung und Tourismus, Kiel, Germany.

Stefan, H.G. \& Preud'homme, E.B. (1993). Stream temperature estimation from air temperature. Water Resour Bull., 29, 27-45.

Tadajewska, M. (2000). White bream (Blicca bjoerkna L.). In: Brylińska M. (ed.) Freshwater fish of Poland. PN, Warszawa, 249-257 (In Polish).

Thompson, A. L. (1950). Factors determining the breeding seasons of birds: an introductory review. Ibis, 92, 173-184.

Vernadsky, V. I. (1923). A plea for the establishment of a biogeochemical laboratory. The Marine Biol. Stat. of Part Erin Annual Report, 37, 38-43.

Vernadsky, V. I. (1926). The Biosphere. Nauchntekhn. izd-vo, Leningrad (in Russian).

Visser, M.E., Caro, S.P., van Oers, K., Schaper, S.V. \& Helm, B. (2010). Phenology, seasonal timing and circannual rhythms: towards a unified framework. Phil. Trans. R. Soc. B365, 3113-3127. (doi:10.1098/rstb. 2010.0111)

Wielgosz, S. \& Tadajewska, M. (1988). Factors determining diet composition and food availability for bream Abramis brama (L.) and white bream Blicca bjoerkna (L.) in Włocławek Dam Reservoir. Acta Ichthyologica Et Piscatoria, 18(1), 79-100.

Ye, L. \& Grimm, N.B. (2013). Modelling potential impacts of climate change on water and nitrate export from a midsized, semiarid watershed in the US Southwest. Clim. Chang. 120, 419-431.

Yılmaz, S., Yazıcıoğlu, O., Erbaşaran, M., Esen, S., Zengin, M. \& Polat, N. (2012). Length-weight relationship and relative condition factor of white bream, Blicca bjoerkna (L., 1758), from Lake Ladik, Turkey. Journal of the Black Sea/Mediterranean Environment 18(3), 380-387.

Yılmaz, S., Yazıcıoğlu, O., Yazıcı, R. \& Polat, N. (2015). Age, growth and reproductive period of white bream, Blicca bjoerkna (L., 1758) in Lake Ladik, Turkey. Limnofish, 1(1), 9-18.

\section{Citation:}

Bondarev, D., Kunah, O., Zhukov, O. (2018). Assessment of the impact of seasonal patterns climatic conditions on spawning events of the white bream Blicca bjoerkna (Linnaeus, 1758) in astronomical and biological time. Acta Biologica Sibirica, 4 (2), 61-77.

Submitted: 15.03.2018. Accepted: 29.04.2018

cross ref http://dx.doi.org/10.14258/abs.v4i2.4125

(C) 2018 by the authors. Submitted for possible open access publication under the terms and conditions of the

Creative Commons Attribution (CC BY) license (http://creativecommons.org/licenses/by/4.0/). 